the legs and abdomen. No further outbreaks occurred after the exclusion of fish from the diet. Of questionable significance is the finding of moderate skin-test reactions to fish, shellfish, cheese, milk, grasses, house dust, and dust-mite despite the absence of a history of any atopic reactions in the past at all.

B W S ROBINSON Rochford Hospital,
Rochford, Essex

Jensen, B, Acta Medica Scandinavica, 1955, 152, 61. 2 Alexander, H L, and Evermann, E H, Archives of Dermatology and Syphilology, 1927, 16, 322 ${ }^{3}$ Ackroyd, J F, American fournal of Medicine, 1953, 14,

\section{Mucocutaneous lymph node syndrome}

SIR,-Your leading article (12 February, $\mathrm{p}$ 407) on mucocutaneous lymph node syndrome (MLNS) came out a week after we had diagnosed our first case at this hospital. The purpose of this letter is merely to report that it is undoubtedly occurring in England.

The patient was an 18-month-old West Indian boy and the findings were so striking that we do not think we could have missed it before. In fact the description in your leading article of a typical case is such that we could use the wording to describe our patient. He became acutely ill with fever, dry lips, red mouth, and a strawberry tongue. Some three days later he developed a rash over his hands and feet in a glove-and-stocking distribution. The skin became indurated and oedematous (though only for a short period was there pitting). The skin of his fingers and toes then desquamated, like the cast of a snake's skin rather than in small flakes. He had cervical adenitis which did not suppurate and investigations showed polymorphonuclear leucocytosi and raised ESR, but all other tests for specific infection, including viral, were negative. The illness has lasted some three weeks and he is steadily recovering now.

If, as you say, this is a new disease we clinicians should be aware of it. If the features are as striking as our case it is unlikely that we shall miss them.

J W SCOPES J A HulsE

Department of Paediatrics, St Thomas's Hospital,

\section{Pancreatic diagnosis}

SIR,-We were sad to read how unlucky Dr P B Cotton and Dr R B Stern (15 January, $p$ 166) have been in their experience of pancreatic radioisotope scans. With such results one would indeed conclude that scanning has no value. However, reviewing the literature recently, ${ }^{1}$ we found no other results as poor and, in our hands, scanning has consistently shown a low false-negative rate. Spencer et $a l^{2}$ have reported similar experience in a district general hospital service.

Grey-scale ultrasound offers greater potential in distinguishing between carcinoma and chronic pancreatitis. However, identification of the normal pancreas can be difficult and a significant incidence of false-negative results has been reported-at least $10 \%$ in carcinoma of the pancreas ${ }^{3}$ and somewhat greater in chronic pancreatitis. ${ }^{4}$ Thus in the absence of further evaluation ultrasound alone cannot be relied upon in excluding pancreatic disease.
We value radioisotope scanning in avoiding dependence on clinical judgment and endoscopic pancreatography (ERCP) alone. As a screening test we feel it can avoid subjecting to ERCP a considerable proportion of patients with a normal pancreas. Ultrasonography can similarly play a vital role in avoiding the hazards of ERCP in a patient with a pseudocyst.

Although Drs Cotton and Stern say that recurrent pain and hyperamylasaemia characterise chronic pancreatitis with a normal pancreatogram, we did not detect a raised serum amylase in our two patients with this combination (27 November, p 1307)

We are by no means satisfied with our diagnostic abilities in pancreatic disease. Our recommendations are based on an attempt to minimise patient discomfort and to achieve the best overall yield from currently available tests.

C J Mitchell E Elias

Royal Free Hospital

J E AGNEW

London NW3

' Agnew, J E, Maze, M, and Mitchell, C J, British Agnew, J E, Maze, M, and Mitche Sournal of Radiology, 1976, 49, 979.
153 . A M, et al, British Medical fournal, 1974, 4, Hancke, S, fournal of Clinical Ultrasound, 1976, 4, 223.
${ }^{3}$ Doust, B D, and Pearce, J D, Radiology, 1976, 120,653.

\section{Cardiomyopathy after gonadotrophin treatment}

SIR,-We have recently observed two brothers who developed a cardiomyopathy which in both was fatal after a relatively short time. Both had received injections of human chorionic gonadotrophin for undescended testes earlier in their lives and we wonder whether there is a causal connection between these two events.

In 1964 the younger brother was found to have an undescended right testis at the age of $7 \frac{1}{2}$ years. He was treated with injections of chorionic gonadotrophin $1000 \mathrm{IU}$ intramuscularly weekly for 12 weeks. This failed to bring the testis down and he therefore underwent orchidopexy at the age of 9 . At this time (1967) his older brother, who was then 12 , was found to have undescended testes too, and he received the same course of hormone treatment

At the age of 19 the older brother developed heart failure with paroxysmal tachycardia and numerous haemoptyses, and in spite of intensive treatment died of intractable heart failure in 1974 At post-mortem the heart was found to be grossly enlarged. Both ventricles were markedly dilated and hypertrophied and the myocardium appeared fibrotic to the naked eye. There was no valvular abnormality or endocardial fibrosis and the coronary vessels were normal. Histological examination showed only areas of fibrosis scattered throughout the myocardium with the muscle fibres themselves apparently normal. Examination of some skeletal striated muscles showed no abnormality. There were no other useful findings.

At the age of 18 the younger brother developed gross heart failure with generalised heart enlargement, and in spite of treatment he steadily deteriorated. He had recurrent attacks of supraventricular tachycardia which were first controlled with beta-blocking agents. However, in spite of intensive medication his condition steadily deteriorated and the arrhythmias became uncontrollable. He died in May 1976 and the postmortem findings were essentially identical with those of his brother.

None of the four sibs ( 3 boys and 1 girl) show any evidence of cardiomyopathy so far; none of them has received hormone injections. The parents are healthy and there is no family history of cardiomyopathy or any other cardiac disorder. We have reported the two case histories to the Committee on Safety of Medicines and would be interested to know of any others which may resemble them.

We are grateful to Dr Dennis Deuchar, physician in charge of the cardiac department at Guy's Hospital, for his advice on reporting these two cases and for supplying us with the post-mortem findings.

T W I LOVEL

G D PORTER

Andover, Hants

\section{Rubella reinfection?}

SIR,-Dr J A M Snijder and others (1 January, p 23) report two cases of suspected congenital rubella in which the diagnosis was established by demonstration of rubella IgM antibodies in cord blood. In their comments the authors state that "Case 2 was probably a case of reinfection." In this connection they refer to a report by us. We should like to stress that, as reported later, ${ }^{1}$ our case was not one of reinfection. The low haemagglutination inhibition (HI) activity in the first serum specimen from our patient was first thought to be due to antibody, since the activity was recovered in the IgG-containing fractions after sucrose gradient centrifugation. Later, when we performed flotation centrifugation, the HI was shown to be due to a lipoprotein, being accordingly a non-specific inhibitor. ${ }^{3}$ The possible occurrence of residual inhibitors by conventional procedures was further studied by one of us. ${ }^{4}$ It was shown that the heparin manganese chloride procedure did not remove very low density lipoprotein and high density lipoprotein, which are rubella haemagglutination inhibitors. ${ }^{3}$ Kaolin removed inhibitors more efficiently but failed occasionally, as in our reported case.

It would be of interest to know if $\mathrm{Dr}$ Snijder and his colleagues have considered the possibility of a false-positive reaction.

GUNNAR HAUKENES K HARAM Claus O Solberg

University Clinic,
Bergen, Norway

'Haukenes, G, Acta Pathologica et Microbiologica Scandinavica, Sect B, 1973, 81, 719. England, G, Haram, K, and Solberg, C O, New England fournal of Medicine, 1973, 289, 429.
Blom, $\mathrm{H}$, and Haukenes, $\mathrm{G}$, Medical Microbiology and Immunology, 1974, 159, 271 . Immunology, 1974, 159, 21. Medical Microbiology and
Immunology, 1975, 161, 99 .

\section{Geriatricians v psychogeriatricians}

SIR,-When and how is the conflict between psychogeriatricians and geriatricians going to be settled?

There comes a time when the elderly demented patient requires long-term care. The often infirm relatives are unable to cope despite district nursing, bath attendants, day hospital care, sheet cleaning services, home helps, and meals on wheels; but the general practitioner is told that long-term care is not indicated or even unavailable.

Psychogeriatric wards are unwilling to accept a patient with any medical condition greater than an ingrowing toenail, but geriatric wards are reluctant to accept any patient who exhibits even a little confusion. As a result the 